\title{
Layanan Mandiri di Perpustakaan SMA Negeri 5 Magelang: Menjawab Tantangan Generasi Milenial
}

\author{
Suryanto \\ Institut Agama Islam Negeri (IAIN) Salatiga \\ E-mail: suryanto@iainsalatiga.ac.id
}

\begin{abstract}
School library is a library located in a school that shelters it. The library has the main objective, namely to support teaching and learning activities. In the current era, pemustaka in senior high schools (SMA) are users who are classified as the millennial generation. Millennial generation has characteristic of making technology a lifestile. Millennials want speed in their every life. The speed at which they wanted made them prefer something simple. Millennials are also more comfortable using technology so that they can do things independently and in a structured manner. Libraries need to innovate in providing services to visitors to match the characteristics of the millennial generation. SMA Negeri 5 Magelang Library implements independent services in responding to the challenges of the millennial generation. The implementation of self-service in the SMA Negeri 5 Magelang Library can be said to be easy and simple. However, there is a need for hardware upgrades so that self-service can run better. It should also be noted regarding security and librarians must be diligent in doing database backups so that at any time when a problem occurs, the data is well preserved.
\end{abstract}

Keywords: Millennial Generation; Self Service; School Library, SMA Negeri 5 Magelang

\begin{abstract}
Abstrak
Perpustakaan sekolah merupakan perpustakaan yang terletak pada suatu sekolah yang menaunginya. Perpustakaan tersebut memiliki tujuan utama yaitu untuk mendukung kegiatan belajar mengajar. Di era seperti sekarang ini, pemustaka di Sekolah Menengah Atas (SMA) merupakan pemustaka yang tergolong sebagai generasi milenial. Generasi milenial memiliki karakteristik yaitu menjadikan teknologi sebagai lifestile. Generasi milenial menginginkan kecepatan dalam setiap kehidupan mereka. Kecepatan yang mereka inginkan mengakibatkan mereka lebih menyukai sesuatu yang simple. Generasi milenial juga lebih nyaman menggunakan teknologi sehingga mereka dapat melakukan sesuatu secara mandiri dan terstruktur.
\end{abstract}

Tik Ilmeu : Jurnal Ilmu Perpustakaan dan Informasi

IAIN Curup | p-issn: 2580-3654; e-issn:2580-3662

DOI: $10.29240 /$ tik.v5i1.2164 
Perpustakaan perlu berinovasi dalam memberikan layanan kepada pemustaka agar sesuai dengan karakteristik generasi milenial. Perpustakaan SMA Negeri 5 Magelang menerapkan layanan mandiri dalam menjawab tantangan generasi milenial tersebut. Penerapan layanan mandiri di Perpustakaan SMA Negeri 5 Magelang dapat dikatakan mudah dan simple. Namun perlu adanya peningkatan hardware agar layanan mandiri dapat berjalan lebih baik. Perlu diperhatikan juga mengenai keamanan serta pustakawan harus rajin melakukan backup database agar sewaktu-waktu ketika terjadi permasalahan, data tetap terjaga dengan baik.

Kata Kunci: Generasi Milenial, Layanan Mandiri, Perpustakaan Sekolah, SMA Negeri 5 Magelang

\section{A. PENDAhULUAN}

Perpustakaan sekolah merupakan perpustakaan yang terletak pada suatu sekolah yang menaunginya. Perpustakaan tersebut memiliki tujuan utama yaitu untuk mendukung kegiatan belajar mengajar. Layanan perpustakaan yang sesuai dengan karakteristik pemustakanya akan mampu memberikan dampak positif terhadap ketertarikan pemustaka dalam menggunakan perpustakaan. Ketertarikan tersebut akan mampu meningkatkan minat kunjung dan minat pinjam pemustaka.

Di era seperti sekarang ini, pemustaka di sekolah, khususnya Sekolah Menengah Atas (SMA) adalah pemustaka yang merupakan generasi milenial. Generasi milenial merupakan generasi yang sangat dekat dengan teknologi, bahkan teknologi sudah seperti lifestile (Wahana, 2015). Teknologi menjadi sesuatu yang sangat penting bagi mereka dalam menghabiskan keseharian mereka. Perpustakaan perlu memanfaatkan teknologi dalam pengelolaan perpustakaan, terutama yang berhubungan dengan pemustaka.

Generasi milenial memiliki karakteristik yang menginginkan sesuatu secara cepat (Wahana, 2015). Layanan perpustakaan yang lamban akan mengakibatkan pemustaka kurang puas terhadap layanan yang mereka dapatkan. Perpustakaan perlu memberikan terobosan baru terhadap layanan mereka agar layanan menjadi cepat. Layanan yang cepat harus mampu meminimalisir antrian ketika pemustaka melakukan peminjaman.

Generasi milenial juga memiliki karakteristik menginginkan kesimpelan (Wahana, 2015). Kesimpelan dalam melakukan layanan menjadi daya tarik tersendiri bagi pemustaka ketika akan melakukan peminjaman buku. Mereka akan lebih tertarik melakukan peminjaman ketika proses melakukan peminjaman simple. 
Karakteristik yang perlu diperhatikan oleh perpustakaan adalah generasi milenial lebih suka dengan sesuatu yang mandiri dan terstruktur dalam penggunaan teknologi (Wahana, 2015). Hal ini menunjukkan bahwa pemustaka lebih senang melakukan sesuatu sendiri dengan bantuan teknologi. Begitu juga ketika akan melakukan peminjaman buku di perpustakaan, pemustaka lebih senang apabila mereka diberi kepercayaan untuk melakukan peminjaman secara mandiri mulai dari pencarian, peminjaman dan pengembalian buku.

Terlebih lagi menurut Undang-Undang No. 43 Tahun 2007 tentang Perpustakaan pasal 23 ayat 5 menyebutkan bahwa perpustakaan sekolah/madrasah mengembangkan layanan perpustakaan berbasis teknologi informasi dan komunikasi (Indonesia, 2007). Hal ini menunjukkan bahwa perpustakaan sekolah harus memberikan layanan kepada pemustaka menggunakan teknologi. Perpustakaan yang belum menerapkan layanan berbasis teknologi dapat dikatakan tidak sesuai dengan Undang-Undang tersebut.

Perpustakaan SMA Negeri 5 Magelang merupakan salah satu perpustakaan yang berada di lingkungan pendidikan yang pemustakanya adalah siswa yang merupakan generasi milenial. Oleh karena itu perlu inovasi dalam memberikan layanan kepada pemustaka agar sesuai dengan karakteristik generasi milenial. Penerapan layanan yang tepat akan mampu meningkatkna minat kunjung dan minat pinjam pemustaka sehingga tujuan dari perpustakaan sekolah sebagai penunjang kegiatan belajar mengajar akan tercapai.

Mulai tahun pelajaran 2015/2016 sampai dengan sekarang, perpustakaan SMA Negeri 5 Magelang menerapkan layanan mandiri sebagai solusi inovatif dalam memberikan layanan kepada pemustaka. Layanan mandiri tersebut ternyata memberikan kepuasan yang sangat tinggi kepada pemustaka. Hal ini terbukti dari hasil penelitian yang menyebutkan bahwa pengaruh penerapan layanan mandiri terhadap kepuasan siswa mencapai 66,1\% (Suryanto, 2018). Oleh karena itu, layanan mandiri mampu menjadi alternatif yang sangat baik dalam memberikan layanan kepada pemustaka.

Penelitian ini merupakan penelitian studi kasus. Penelitian dilaksanakan di Perpustakaan SMAN Negeri 5 Magelang. Penyajian data menggunakan metode deskriptif. Penelitian ini menjawab mengenai seperti apa dan bagaimana penerapan layanan mandiri di Perpustakaan SMA Negeri 5 Magelang. 


\section{B. HASIL DAN PEMBAHASAN}

\section{Pengertian Layanan Mandiri}

Layanan mandiri merupakan layanan yang membutuhkan interaksi dengan teknologi sehingga pemustaka dapat melakukan pelayanan untuk pemustaka sendiri (Beatson dkk., 2006; Meuter dkk., 2000). Layanan ini memungkinkan pemustaka untuk melakukan peminjaman, pengembalian, atau kegiatan lain yang berhubungan dengan perpustakaan secara mandiri (Suryanto, 2019). Layanan mandiri akan berjalan baik apabila teknologi yang digunakan memadai sesuai dengan spesifikasi yang ditentukan untuk menjalankan layanan mandiri tersebut (Dewi, 2018; Sihombing, 2017).

\section{Jenis layanan Mandiri}

Perpustakaan SMA Negeri 5 Magelang menerapkan berbaga macam layanan mandiri antara lain, pertama peminjaman mandiri, yaitu proses peminjaman buku yang dilakukan pemustaka secara sendiri dengan bantuan sebuah komputer. Kedua pengembalian mandiri, yaitu proses mengembalikan buku yang dilakukan oleh pemustaka secara mandiri menggunakan komputer. Ketiga perpanjang mandiri merupakan proses memperpanjang masa berlaku peminjaman buku yang telah jatuh tempo secara mandiri menggunakan komputer.

\section{Hardware dan Software Layanan Mandiri}

Hardware dan software merupakan bagian yang tidak dapat terpisahkan dalam teknologi. Hardware/perangkat keras membangun sebuah komputer yang terdiri dari komponen sistem komputer berupa perangkat elektronik (Dewi Anggadini, 2013; Situmorang \& Sembiring, 2016). Sedangkan Software/perangkat lunak berfungsi sebagai perantara/interface antara hardware dan brainware. Software/ perangkat lunak terdiri dari komponen sistem komputer yang berupa aplikasi atau program yang tertanam pada hardware (Sutabri, 2012).

Hardware yang diperlukan dalam menjalankan layanan mandiri adalah sebagai berikut:

a. komputer server (Untuk Install SLiMS),

b. komputer client (Untuk Install SLiMS Desktop),

c. jaringan Local Area Network (LAN),

d. printer kasir, dan

e. barcode scanner. 
Sedangkan software yang digunakan adalah Senayan Library Management System (SLiMS) ${ }^{1}$ dan SLiMS Desktop (Hamim, 2016). ${ }^{2}$ SLiMS digunakan sebagai server untuk menjalankan otomasi perpustakaan, sedangkan untuk layanan mandiri menggunakan SLiMS Desktop. SLiMS Desktop dapat berjalan baik pada sistem operasi Windows.

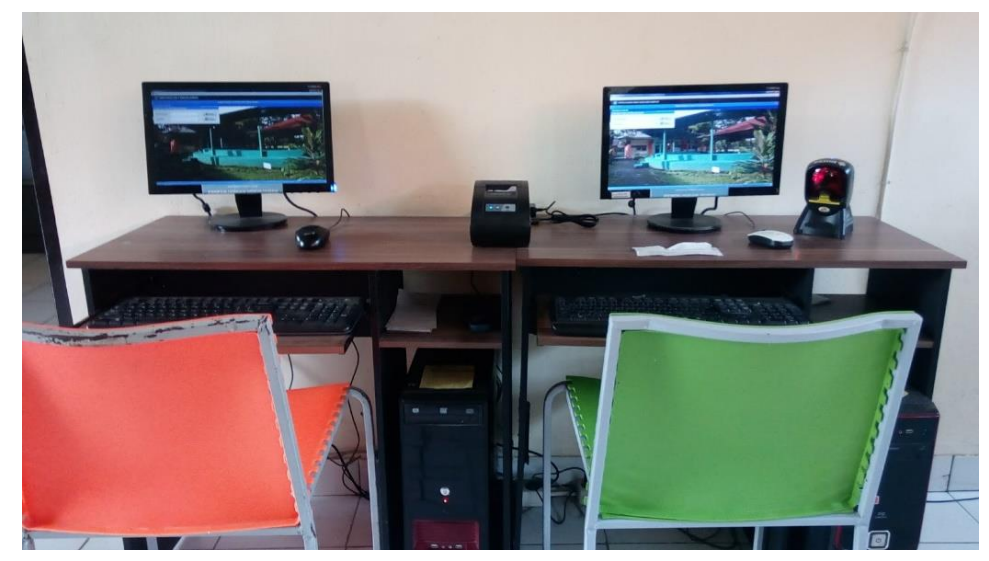

Gambar 1. Perangkat untuk Peminjaman Mandiri

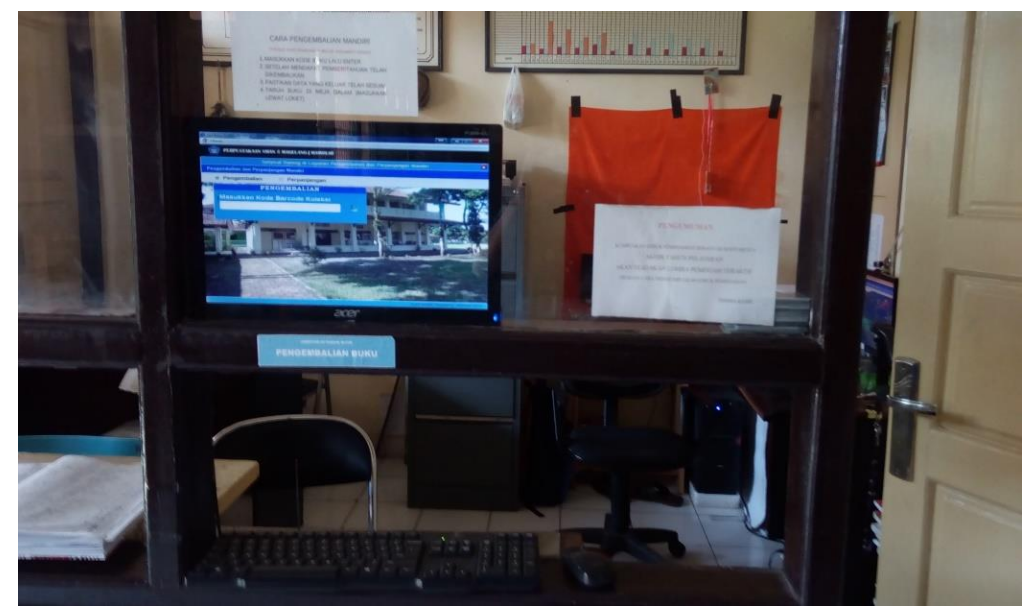

Gambar 2. Perangkat untuk Perpanjang dan Pengembalian Mandiri

${ }^{1}$ SLiMS dapat diunduh di slims.web.id

${ }^{2}$ SLiMS desktop merupakan aplikasi yang dibuat oleh Muhammad Hamim. Dia merupakan salah satu pustakawan di perpustakaan STAIN Kediri. Penulis mendapatkan aplikasi SLiMS Desktop secara gratis dengan mengunduh di http://slims.web.id/goslims/?wpdmpro=slimsdesktop-muhamad-hamim 


\section{Instalasi SLiMS Desktop}

SLiMS Desktop merupakan program aplikasi yang berdiri sendiri dengan melakukan pengambilan data dari database Senayan (SLiMS) (Hamim, 2016). SLiMS Desktop diinstall berbasis jaringan dan dapat dijalankan pada sistem operasi Windows. Perpustakaan SMA Negeri 5 Magelang menggunakan Windows 7.

Penginstalan cukup dengan meng-copy paste folder SLiMS Desktop pada Drive: D atau Drive: E. Di dalam folder SLiMS Desktop terdapat file bernama SLiMS Desktop.exe. Jalankan file SLiMS Desktop.exe maka akan muncul pop up yang menjelaskan bahwa SLiMS Desktop tidak terhubung dengan database dan dipersilahkan untuk menyeting koneksi dengan database.

Konfigurasi koneksi database dilakukan dengan cara meng-klik "home" kemudian "koneksi", maka akan muncul halaman untuk konfigurasi koneksi database.

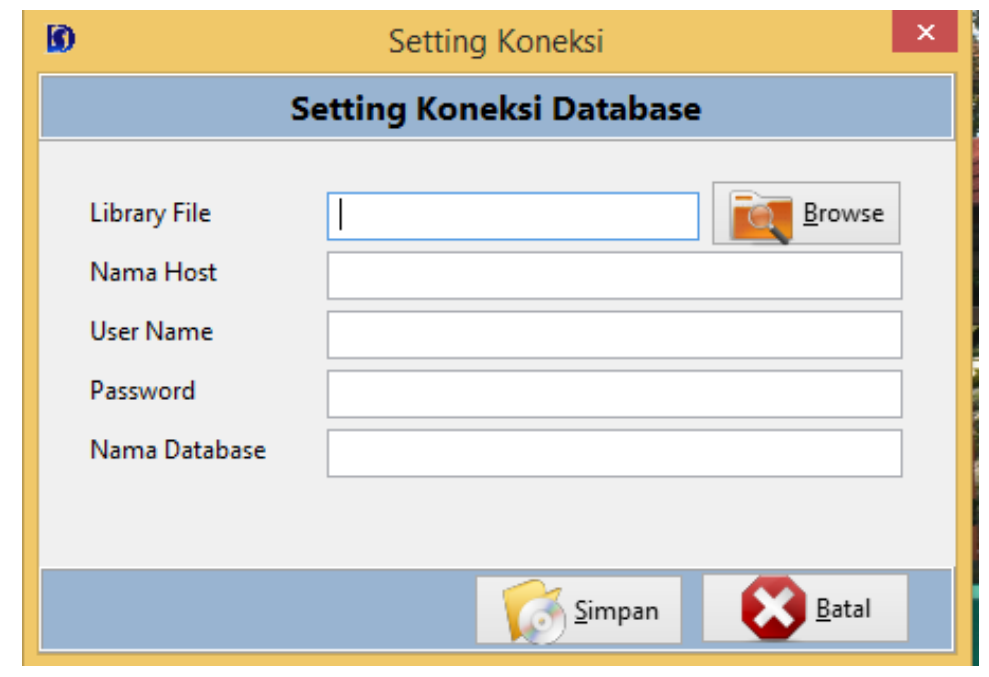

Gambar 3. Setting Koneksi Database

Pada menu koneksi aplikasi SLiMSDesktop.exe, konfigurasinya adalah sebagai berikut (Hamim, 2016).

a. Library File : letak file "libmysql.dll" berada pada folder SLiMSDesktop.

b. Nama host : Host tempat database berada.

c. User Name : User name mysql 
d. Password : Password mysql

e. Nama Database : Nama database SliMS yang akan dikoneksikan

\section{Peminjaman Mandiri}

Peminjaman mandiri merupakan layanan kepada pemustaka yang memungkinkan pemustaka meminjam buku sendiri tanpa perlu bertatap muka dengan pustakawan. Pemustaka hanya perlu mengoperasikan komputer yang telah disediakan. Proses peminjaman hanya dengan 4 tahap maka buku sudah terpinjam.

Tahap peminjaman mandiri adalah sebagai berikut,

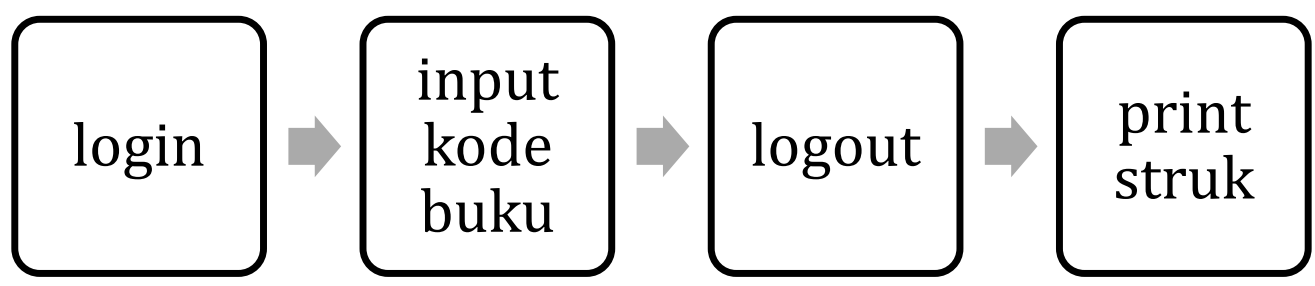

Ketika akan melakukan peminjaman, pemustaka mengetikkan kode anggota/nis dan password pada kolom yang tersedia.

Setelah melakukan login maka akan muncul tampilan mengenai informasi pemustaka, informasi peminjaman, dan menu ganti password seperti pada gambar berikut.

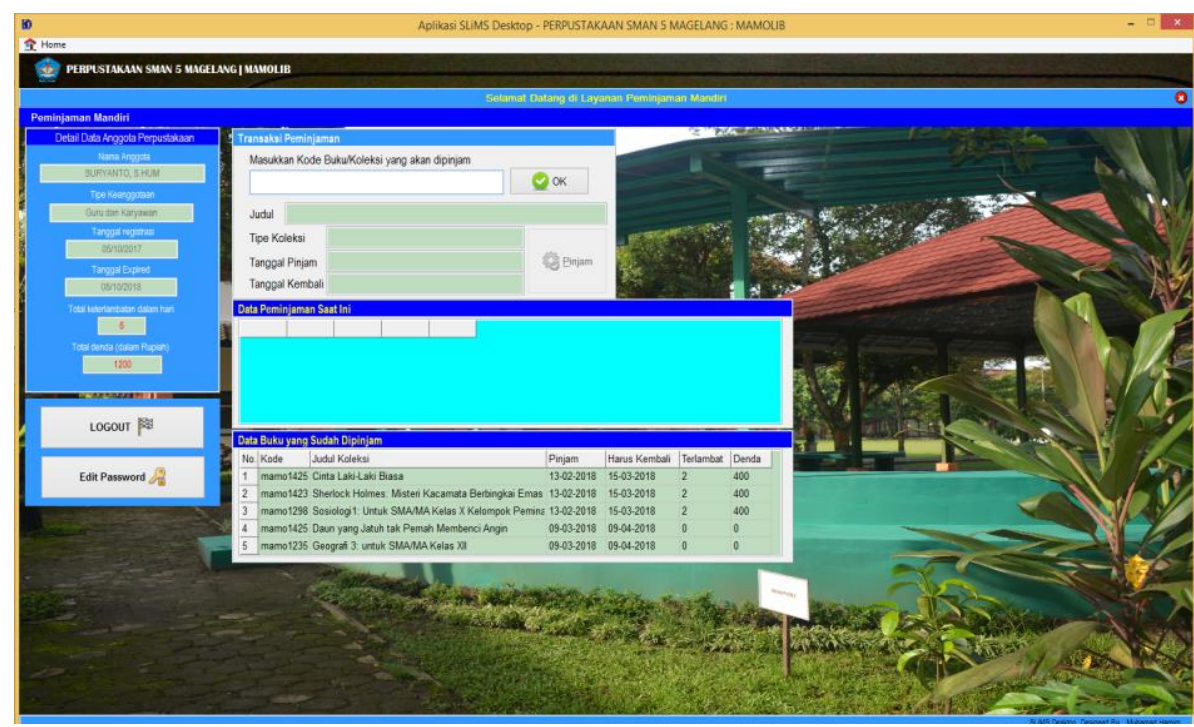

Gambar 4. Halaman Peminjaman Buku 
Pemustaka kemudian mengetikkan atau men-scan barcode kode buku yang tertera pada label buku. Setelah semua buku yang akan dipinjam telah terdata, kemudian pemustaka mengklik logout. Proses peminjaman selesai dengan ditandai struk peminjaman yang keluar dari printer kasir yang telah disediakan.

\section{Perpanjang Mandiri}

Perpanjang mandiri merupakan fasilitas yang memungkinkan pemustaka untuk melakukan perpanjangan secara mandiri tanpa harus bertatap muka dengan pustakawan. Perpanjang mandiri hanya bisa dilakukan apabila buku yag dipinjam belum mengalami keterlambatan pengembalian. Proses perpanjang mandiri cukup simpel karena hanya dengan mengetikkan atau men-scan kode buku yang akan diperpanjang maka buku telah berhasil diperpanjang sesuai dengan ketentuan yang berlaku.

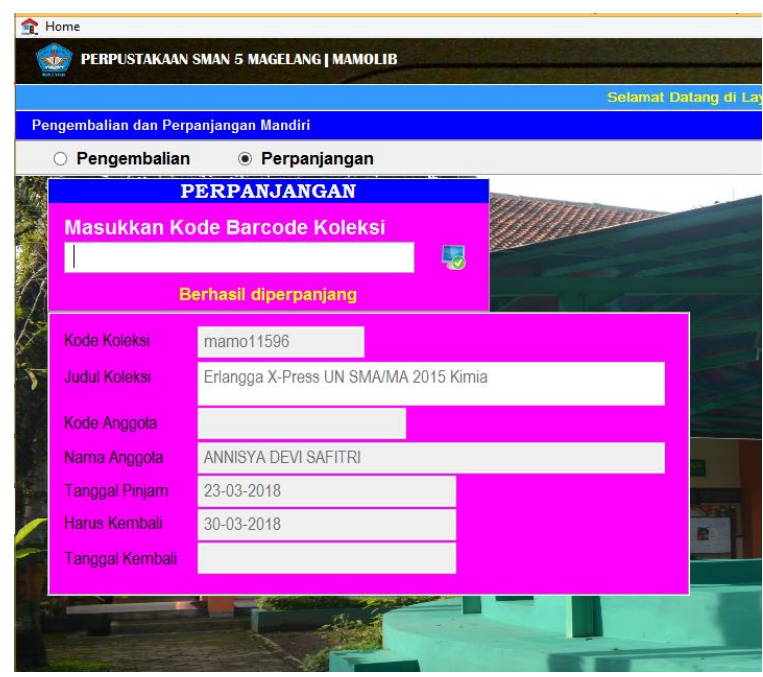

Gambar 5. Tampilan Pepanjang Mandiri Berhasil

\section{Pengembalian Mandiri}

Pengembalian Mandiri merupakan fasilitas yang memungkinkan pemustaka untuk melakukan pengembalian buku secara mandiri tanpa bertatap muka dengan pustakawan. Pengembalian mandiri hanya bisa dilakukan apabila buku yang akan dikembalikan belum dalam keadaan terlambat. Proses peminjaman juga sangat simpel, sama dengan proses ketika perpanjang mandiri, yaitu dengan cara mengetik atau men-scan barcode kode buku pada kolom yang tersedia. Setelah berhasil dikembalikan, kemudia 
buku ditaruh pada tempat yang telah disediakan. Pengembalian berhasil apabila muncul pemberitahuan seperti pada gambar berikut

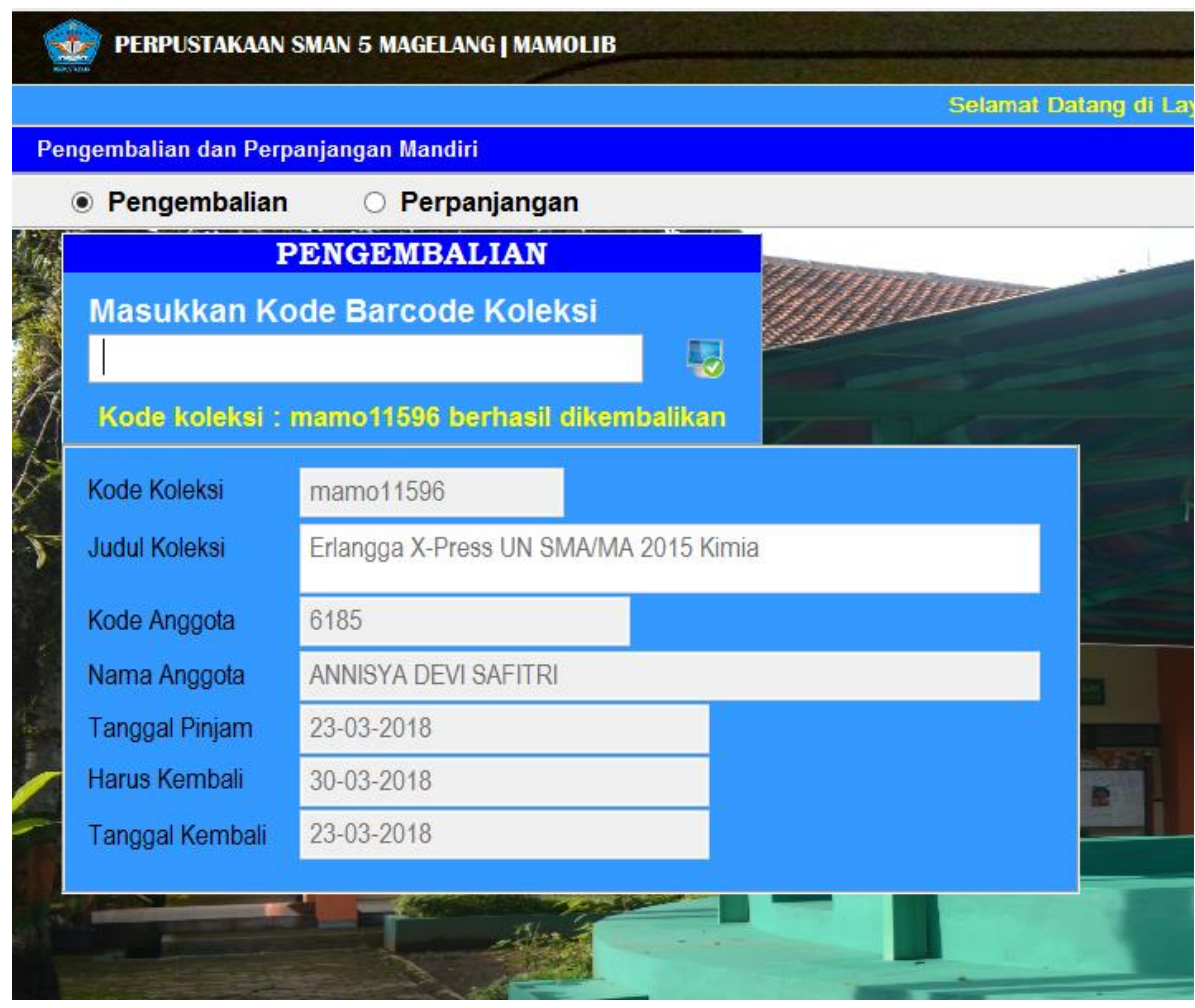

Gambar 6. Tampilan Pengembalian Mandiri Berhasil

\section{KESIMPULAN}

Dari uraian diatas dapat disimpulkan bahwa dalam melayani pemustaka yang merupakan generasi milenial, perpustakaan SMA Negeri 5 Magelang menerapkan Layanan Mandiri. Layanan Mandiri di perpustakaan SMA Negeri 5 Magelang terdiri dari peminjaman mandiri, perpanjang mandiri dan pengembalian mandiri. Penerapan dan penggunaan layanan mandiri mudah dan simpel.

Penulis juga memberikan beberapa saran yaitu perlu adanya penguatan dari segi hardware sehingga layanan mandiri dapat berjalan dengan baik. Keamanan perlu diperhatikan agar tidak ada pihak yang dirugikan. Backup database dilakukan secara berkala untuk memperkecil kemungkinan kehilangan data ketika hardware atau software rusak/bermasalah. 


\section{DAFTAR RUJUKAN}

Beatson, A., Coote, L. V., \& Rudd, J. M. (2006). Determining Consumer Satisfaction and Commitment Through Self-Service Technology and Personal Service Usage. Journal of Marketing Management, 22(7-8), 853-882. https://doi.org/10.1362/026725706778612121

Dewi Anggadini, S. (2013). Analisis sistem informasi manajemen berbasis komputer dalam proses pengambilan keputusan. Majalah Ilmiah UNIKOM.

Dewi, N. I. (2018). Efektivitas Layanan Sirkulasi Melalui Sistem Layanan Mandiri di UPT. Perpustakaan Pusat Universitas Muhammadiyah Malang.

Hamim, M. (2016). Penerapan Peminjaman Mandiri Berbasis SLiMS Versi Desktop: Studi Kasus di Perpustakaan STAIN Kediri. Pustakaloka: Jurnal Kajian Informasi dan Perpustakaan, 8(1), 34-56. https://doi.org/10.21154/pustakaloka.v8i1.495

Indonesia, R. (2007). Undang-Undang nomor 43 tahun 2007 tentang perpustakaan. Jakarta: Perpustakaan Nasional.

Meuter, M. L., Ostrom, A. L., Roundtree, R. I., \& Bitner, M. J. (2000). Selfservice technologies: Understanding customer satisfaction with technology-based service encounters. Journal of marketing, 64(3), $50-64$.

Sihombing, M. (2017). Layanan Mandiri Perpustakaan Universitas Negeri Medan (UNIMED).

Situmorang, O., \& Sembiring, A. S. (2016). Perancangan Aplikasi Pembelajaran Teknologi Informasi dan Komunikasi (TIK) Dengan Menggunakan Metode Computer Based Instruction. JURIKOM (Jurnal Riset Komputer), 3(1).

Suryanto. (2018). PENGARUH PENERAPAN TECHNOLOGY-BASED SELF-SERVICE TERHADAP KEPUASAN SISWA PADA LAYANAN PEMINJAMAN DI PERPUSTAKAAN SMA NEGERI 5 MAGELANG [Masters, UIN SUNAN KALIJAGA]. http://digilib.uinsuka.ac.id/30562/

Suryanto, S. (2019). PERSEPSI PEMUSTAKA TERHADAP PENERAPAN PEMINJAMAN MANDIRI DI PERPUSTAKAAN SMA NEGERI 5 MAGELANG. Publication Library and Information Science; Vol 3, 
$\begin{array}{llll}\text { No } & 1 & \text { (2019)DO } & -\end{array}$ http://journal.umpo.ac.id/index.php/PUBLIS/article/view/1690

Sutabri, T. (2012). Konsep sistem informasi. Penerbit Andi.

Wahana, H. D. (2015). Pengaruh Nilai-Nilai Budaya Generasi Millennial Dan Budaya Sekolah Terhadap Ketahanan Individu (Studi Di SMA Negeri 39, Cijantung, Jakarta). Jurnal Ketahanan Nasional, 21(1), 14-22. https://doi.org/10.22146/jkn.6890 